\title{
A Model for Measuring and Managing the Impact of Design on the Organization: Insights from Four Companies
}

\author{
Iker Legarda $^{1, * \mathbb{D}}$, Ion Iriarte ${ }^{1, *}$, Maya Hoveskog ${ }^{2} \mathbb{D}$ and Daniel Justel-Lozano ${ }^{1}$ \\ 1 Design Innovation Center (DBZ), Faculty of Engineering, Mondragon Unibertsitatea, Loramendi 4, \\ 20500 Arrasate-Mondragon, Spain; djustel@mondragon.edu \\ 2 School of Business, Innovation and Sustainability, Halmstad University, Kristian IV:s väg 3, \\ 30118 Halmstad, Sweden; maya.hoveskog@hh.se \\ * Correspondence: ilegarda@mondragon.edu (I.L.); iiriarte@mondragon.edu (I.I.)
}

check for updates

Citation: Legarda, I.; Iriarte, I.; Hoveskog, M.; Justel-Lozano, D. A Model for Measuring and Managing the Impact of Design on the Organization: Insights from Four Companies. Sustainability 2021, 13, 12580. https://doi.org/10.3390/ su132212580

Academic Editors: Maria

Socorro Garcia Cascales and Francisco Ortega-Fernandez

Received: 18 September 2021 Accepted: 10 November 2021 Published: 15 November 2021

Publisher's Note: MDPI stays neutral with regard to jurisdictional claims in published maps and institutional affiliations.

Copyright: (c) 2021 by the authors. Licensee MDPI, Basel, Switzerland. This article is an open access article distributed under the terms and conditions of the Creative Commons Attribution (CC BY) license (https:// creativecommons.org/licenses/by/ $4.0 /)$.

\begin{abstract}
Increasing numbers of companies are looking to embed design as a strategic capability to meet today's business and social challenges. However, integrating design in an organization is a challenge, due to the scarcity of knowledge on managing this process and measuring its impact. This study presents a model for measuring and managing the impact of design on the organization (DIMM). The model builds on four levels of design impact identified in the literature: results, perception, processes, and design culture. The model was tested with four service companies that have recently developed design capabilities. To this end, those responsible for the integration of design were interviewed, using the model itself as an interview guide to confirm its usefulness and identify possible improvements. The results showed that the model was useful to assess the impact of design on companies with emerging design capabilities, but also as a reflection and management tool to align design with strategic objectives and promote its integration into the organization. Finally, future research should test the model longitudinally, as well as in a broader scope of organizations, to validate its usefulness for organizations with greater design maturity.
\end{abstract}

Keywords: design; design management; sustainable development; design capability; organizational capabilities

\section{Introduction}

The growing complexity of the economic, social and environmental challenges of today $[1,2]$ require project management to bridge new approaches to address uncertain, ill-defined objectives [3]. The traditional view of project management as "a set of concepts, tools and techniques on how to execute projects on time, within budget and to required customer specifications" (p. 719) demonstrated poor performance in highly disruptive contexts [4]. Morris [5] claimed that complex project management needs human-centered approaches to uncover stakeholders' tacit knowledge and support decision-making. Rather than focusing on absolute planning and control, complex projects should be handled with iteration and reflective learning [6]. Mahmoud-Jouini et al. [7] identified three emerging research streams investigating project management in innovative contexts: the introduction of exploration and learning aspects into project management, stakeholder engagement and mobilization, and the role of project management in strategy-making. Interestingly, the same researchers concluded that design, as a human-centered problem-solving approach, could support project management to address those research priorities and endow organizations with capabilities to handle complex and uncertain challenges.

Design is gaining relevance in the management field due to its suitability for exploring, framing, and unlocking convoluted problems [8]. Design processes integrate diverse disciplines such as marketing, social science, operations, and engineering $[9,10]$, and are based on qualitative research to achieve a deep understanding of a particular problem, its context 
and stakeholder needs [11]. Afterward, solutions are sought for the problems and opportunities found through collaborative processes in which visualization tools-visual tools that help to work with abstract ideas, such as experiences and emotions-and prototyping tools are abundant, allowing ideas to become tangible and be evaluated quickly [12-14]. By aligning corporate interests with the interests of other stakeholders in the organization's environment, designers generate innovative solutions to complex challenges, seeking a positive result for all parties $[15,16]$.

Nevertheless, the reality is that companies often find embedding design to be challenging [17-19]. Developing design capabilities is not only about employing specific methods but also requires a cultural change [20]. Companies tend to approach their processes with an internal perspective, organize themselves in "watertight departments", and pursue financial results [20]. Conversely, design-led companies [21] are oriented toward people and context, are multidisciplinary and collaborative and, in addition to financial results, pursue qualitative objectives related to the customer experience.

In-house design knowledge can be developed by accumulating one-off actions such as training, projects and collaboration with design professionals [22]. However, previous research demonstrated that integrating design into the organization can take years until it is consolidated as an organizational capability [23,24]. Furthermore, when design integration is not adequately managed, companies usually revert to their old routines [25]. Although design practice has received considerable academic attention, little research has focused on managing the integration of design in the company $[22,23,26]$, so organizations lack practical guidelines for decision-making [22].

To enhance design capability management, some researchers developed models to overcome the limitations of traditional business metrics [27] and identify organizations' design maturity [28-31]. However, those models only considered qualitative aspects that did not relate design practice directly to achieving strategic objectives and business results. In fact, in some cases, the purpose of the models was not to assist companies in integrating design but to carry out comparative studies to determine the degree of maturity of design among companies in a given territory [28,32]. Therefore, transformation leaders today lack a model that helps them identify the impact of their efforts to develop design capabilities holistically and guide their decision-making.

For that reason, this research aims to develop and critically evaluate a model that assists managers in integrating design capabilities in their organizations by identifying and managing design impact. This would enhance the project management capabilities in organizations to handle complex and uncertain challenges. Thus, this study explores existing models to point out their strengths and limitations and to build on them. The purpose of this new model, called Design Impact Measurement and Management (DIMM), is for the organization to recognize the potential of design to achieve its strategic objectives, to know its degree of design maturity, and to identify the next steps for an enhanced use of design as a source of competitive advantage and sustainable development. The validity of the DIMM model was tested with four service companies with emerging design capabilities.

The article consists of the following sections. Firstly, existing design assessment models are explored to highlight their limitations and strengths and build on them. Secondly, the research method and the construction of the DIMM model are explained. Thirdly, the four case studies with which the model was evaluated are presented. Fourthly, the model's functionality is discussed, based on the research results.

\section{The Impact of Design on the Organization}

Organizations' capacity to use design in their development work is known as design capability [33]. Although previous research approached design capability from different perspectives, Malmberg [33] reviewed the literature to break it down into its principal component dimensions. Firstly, design resources refer to the organization's capacity to allocate human, financial, and material resources to design activities. Secondly, the awareness of design is the organization's understanding of design tools and principles, 
and how they bring value to the organization in its particular business context. Finally, organizations need to develop structures that enable the enactment of design practices.

Today, growing numbers of companies understand design not only as a resource to develop products and services that are more desirable to consumers but also as a "way of doing" that, according to Liedtka [34], allows companies to establish better relationships with their customers, optimizes innovation processes, minimizes the risk and uncertainty of new launches, and contributes to strategic decision-making. As a result, companies can optimize new product (and service) development processes, which are the cornerstone of the business success of many organizations [35,36]. Some previous models thus focused on assessing the efficiency and efficacy of design and development processes [35-37]. Moreover, design supports organizational learning processes by assimilating external knowledge and exploiting that knowledge through the necessary transformations [38,39]. This is especially relevant for responding quickly to ever-changing market demands, competitors' moves and the needs of dynamic manufacturing systems [40-42].

Models for identifying the impact of design on organizations have been driven by both academia and practice. Those models have attracted increasing interest over the last two decades, particularly following the publication of the Design Ladder model by the Danish Design Center [28]. This model ranked Danish organizations' use of design on a scale with four levels: (1) non-design, (2) design as style, (3) design as process, and (4) design as strategy. The Design Ladder contributed to making the strategic value of design visible and encouraged companies to elevate it to a position of greater relevance in strategic decisionmaking. Consequently, the model has been used later by other institutions, such as the European Commission [43] and the UK Design Council [44], to conduct analogous studies in their corresponding industries. In fact, the Design Council has periodically published reports on the state of design in the UK for the last two decades, demonstrating, among other insights, that companies driven by design outperform non-design-driven ones in their financial performance.

Subsequent models such as the Design Management Staircase [29] and the Design Capacity Model [45] made the Design Ladder more sophisticated with the inclusion of additional dimensions, such as design knowledge, design resources, stakeholder involvement, design expertise and design management. These models are oriented to assist organizations in identifying their design maturity. However, their practical usefulness is still questionable because they do not propose specific actions to increase design capability, nor do they accompany organizations longitudinally in the management of design.

Academic research set out to address the flaws of existing models and cover the needs of the practitioner community, to manage the development of design capability in organizations. In particular, scholars investigated the underpinnings of organizational design capabilities to develop practice-oriented design management tools, such as the Design Audit Tool of Moultrie et al. [46] and the Design Management Audit Framework by Topaloğlu and Er [31]. Both models provide a comprehensive understanding of the existing design processes in the organization and how they could be improved. However, they are based on qualitative questionnaires that do not clearly identify the degree to which design processes affect the achievement of business objectives. These tools would be more practical if they connected the results obtained to the "hard" business metrics that rule the organization, to reveal the potential value that is captured through design.

In contrast, the Design Value Scorecard [30] proposed a process to establish quantifiable metrics for those design processes aligned with business strategy. However, Liedtka et al. [47] questioned the usefulness of these metrics alone, arguing that there are also meaningful ways in which design impacts the organization that cannot be identified quantitatively. Therefore, in The Handbook of Design Management, Hands suggested combining quantitative and qualitative metrics to improve design assessment and management [48]. In line with Hands' suggestion, Liedtka et al. [47] argued that business results (usually individually and objectively measurable results) are only "the tip of the iceberg", as they are the cause of prior changes in people's behavior at three levels: 
1. In the first place, we identify the changes in people's perception of the company. It is reasonable to assert that a higher likelihood of customer recommendation will positively impact sales, just as higher employee satisfaction will imply a higher quality of service. At this level, the changes are still measurable-e.g., through satisfaction questionnaires-although the type of information collected is far from the traditional economic/financial indicators and is closer to emotional aspects such as satisfaction, loyalty, brand perception, motivation, etc.

2. Secondly, there are changes in the conversations between people in the organization, for example, companies that spend time discussing customer experience or leaders who encourage their teams to experiment and take risks. These changes are reflected more clearly in design processes, such as an increase in the number of designers on staff, the systematization of design processes, or the use of indicators to manage the customer experience, among others.

3. Thirdly and finally, the integration of design in the company entails changes in the individual mindsets of staff members and, consequently, in the organizational culture, understood as the aggregation of these mindsets. Liedtka et al. [47] explained it with the example of a management team in a financial company that started to think about customers in a more empathetic way, and a food chain that made kitchen staff feel like "chefs".

Thus, Liedtka et al. [47] offered a theoretical framework that related the effects of design on organizational behavior, observed qualitatively, with business outcomes that assessed strategic objectives quantitatively. As the impact of design becomes deeper (to use the iceberg metaphor), behavioral changes and their effects on the organization are more difficult to identify and measure. Changes in organizational culture are subtle and it is not always possible to understand their effects on other levels of the organization. However, the fact that specific ways in which design impacts the organization cannot be quantified with traditional business metrics does not mean that they should not be encouraged and managed. Evidence of the impact of design at different levels contributes to making its value visible and encourages the integration of design in the organization [47]. Changes at deeper impact levels are likely to persist, fostering design integration as a sustained organizational capability [20]. All in all, it should be stressed that Liedtka et al.'s model [47] is a theoretical framework, not a practical tool to assist organizations in developing design capabilities.

Additionally, some strategic consulting firms published their own design assessment tools, similar to those in the models mentioned above. This is the case for McKinsey [49], Koos Service Design [50] and InVision [51]. However, these models did not present substantial changes to the previous ones that were developed by practitioner institutions and scholars, beyond more commercially suggestive appearances, or, at least, the companies did not make them known.

In conclusion, the literature still lacks a model to assist organizations in measuring and managing the impact of design, thus assisting them in developing design capabilities. Organizations need further guidelines on how to develop design capabilities, and the models presented in the literature showed important flaws as practical frameworks for managerial decision-making throughout the process. Traditional financial metrics only serve to measure part of the impact of design [27], while existing design management models do not relate the impact of design to organizational processes and culture to business outcomes. Therefore, this research proposes a model for companies to develop and manage their design capabilities, combining the management of quantitative and qualitative aspects, and connecting changes in perception, processes and organizational culture with strategy and business results, as proposed by Liedtka et al. [47]. The new model builds on the strengths and limitations of previous models, outlined in this section and summarized in Table 1, and contributes practical knowledge on the development of design capability to assist organizations in their change processes [22]. Thus, the study contributes to project management research by investigating how organizations develop human-centered capabilities to handle complex and uncertain challenges. 
Table 1. Purposes, strengths and limitations of models for embedding design in the organization.

\begin{tabular}{|c|c|c|c|c|}
\hline Model & Type & Purpose & Strengths & Limitations \\
\hline Design Ladder [28] & $\begin{array}{l}\text { Scale/ } \\
\text { questionnaire }\end{array}$ & $\begin{array}{l}\text { To identify the degree of } \\
\text { design maturity on a } \\
\text { four-level scale for a } \\
\text { comparative study among } \\
\text { Danish companies. }\end{array}$ & $\begin{array}{l}\text { Pioneer in identifying } \\
\text { different levels in the use } \\
\text { of design. }\end{array}$ & $\begin{array}{l}\text { Description lacks detail. } \\
\text { Aimed at making a } \\
\text { comparison between } \\
\text { organizations. } \\
\text { It does not suggest } \\
\text { improvement measures. }\end{array}$ \\
\hline Design Audit [46] & Questionnaire & $\begin{array}{l}\text { To evaluate design } \\
\text { performance in internal } \\
\text { processes and resulting } \\
\text { products in SMEs }\end{array}$ & $\begin{array}{l}\text { It represents the current } \\
\text { state and the desired state, } \\
\text { to facilitate a plan of action. }\end{array}$ & $\begin{array}{l}\text { A connection with ultimate } \\
\text { business goals is missing. } \\
\text { It is focused on new } \\
\text { product development; } \\
\text { other valuable design } \\
\text { approaches are missing } \\
\text { such as service design, } \\
\text { business models } \\
\text { or strategies. }\end{array}$ \\
\hline $\begin{array}{l}\text { Design } \\
\text { Management } \\
\text { Staircase [29] }\end{array}$ & Matrix & $\begin{array}{l}\text { To identify the degree of } \\
\text { maturity in five } \\
\text { dimensions of design } \\
\text { management, in order to } \\
\text { carry out a comparative } \\
\text { study among nine } \\
\text { European SMEs. }\end{array}$ & $\begin{array}{l}\text { Builds on the Design } \\
\text { Ladder, adding various } \\
\text { dimensions to } \\
\text { design maturity. }\end{array}$ & $\begin{array}{l}\text { It does not propose specific } \\
\text { actions to increase } \\
\text { design capability. } \\
\text { Does not connect design } \\
\text { capability with } \\
\text { business results. }\end{array}$ \\
\hline
\end{tabular}

Conceptual framework to identify the different forms of design impact on an Design Thinking Impact [47]

Scale organization from a people behavior perspective, including less obvious but significant forms for business outcomes.
It reveals that design also influences people's behavior in subtle and unmeasurable, often overlooked ways that significantly impact business results.
It is a conceptual framework, not a practical design evaluation and management tool.
To identify and manage the degree of maturity in five dimensions related to design capability.
It proposes a tool not only to measure but also to manage design.
Design Capacity $\quad$ Radar chart
Model [45]

Design Value

Scorecard [30]
Matrix/ process

To identify and manage the degree of maturity in five dimensions related to design capability.
It proposes a process to use the tool for management purposes.
It does not propose specific actions to increase design capability. Does not connect design capability with business results.

\section{It focuses on "hard} metrics", ignoring other non-measurable aspects of design impact.

The results can be confusing and biased because all questions are open-ended and qualitative in nature.

Does not connect design capability with business results.

Design
Management Audit Questionnaire
Framework [31]

To evaluate an organization's design processes and their connection to strategy.
It consists of a list of open questions that invite reflection on how to improve design processes.

\section{Methodology}

This research aims to develop and critically evaluate a model to identify the impact of design on the organization and assist managers in the development of firm-level design capabilities. The research methodology is based on a Design Science approach $[52,53]$ that is useful when research aims at validating theory, as well as contributing design outcomes [52] - in the case of this article, a model for measuring and managing the impact 
of design in organizations. Design Science research informs initial theories through visual artifacts that are refined through subsequent testing [54].

The procedure followed for the development and evaluation of the model is indicated in Figure 1, and is based on the method employed by Acklin [55], whose research shows a strong influence of the Design Science $[52,53]$ approach that inspired our research methodology. Acklin proposed and evaluated a new model to assist organizations and designers in managing their change efforts through "absorptive capacity" lenses. For that purpose, she created a prototype of her model, evaluated it in real case studies and finally analyzed the results to propose an improved version of the model.

Therefore, the first phase of this research consisted in conducting a literature review to identify the limitations of existing models, identify the research opportunity and establish a theoretical framework—namely, the Design Thinking impact model of Liedtka et al. [47]—on which to build the new model.
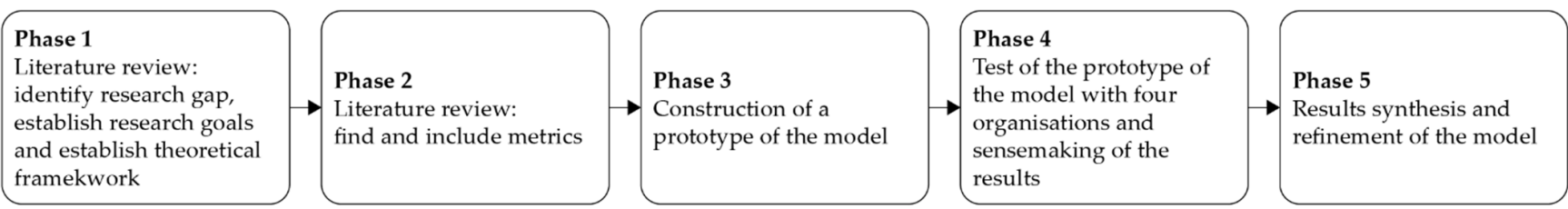

Figure 1. Process followed for the development of the DIMM model.

Next, we turned to the literature to identify metrics in order to assess the impact of design at the different levels described in the previous section. In the next step, a prototype of the model for measuring and managing design impact was developed by integrating the information found in the literature review.

Then, the model was empirically evaluated in four case studies, firstly with the companies Contcen and FoodCollective, and secondly with Bankop and Propind (the real names of the companies have been substituted to preserve their anonymity). The researchers acquired knowledge gradually, in cycles of intervention, test and sense-making of results [14]. As indicated in Table 2, the four participant companies were service organizations with emerging design capabilities. In all cases, they had carried out design projects for less than two years before the tests were conducted.

Table 2. Comparison between the case studies.

\begin{tabular}{|c|c|c|c|c|}
\hline Business & Contcen & FoodCollective & Bankop & Propind \\
\hline Sector & $\begin{array}{l}\text { Contact center and } \\
\text { customer care services }\end{array}$ & $\begin{array}{l}\text { Industrial catering } \\
\text { services }\end{array}$ & Bank and financial services & $\begin{array}{l}\text { Industrial Property } \\
\text { consulting services }\end{array}$ \\
\hline Size & Medium ( 200 people) & Large $(+11,000$ people) & Large (+2500 people) & Small ( 20 people) \\
\hline Interview date & 24 February 2020 & 6 March 2020 & 23 March 2021 & 12 March 2021 \\
\hline $\begin{array}{l}\text { Research } \\
\text { participants }\end{array}$ & $\begin{array}{l}\text { Director of Projects and } \\
\text { Technology } \\
2 \text { Designers } \\
\text { Team Coordinator } \\
\text { Project Manager }\end{array}$ & $\begin{array}{l}\text { Director of Corporate } \\
\text { Innovation } \\
\text { Sales Manager }\end{array}$ & $\begin{array}{l}\text { Customer and Service } \\
\text { Development Leader } \\
2 \text { Customer and Service } \\
\text { Development Technicians } \\
\text { Service and UX designer }\end{array}$ & $\begin{array}{l}\text { Managing Director } \\
\text { IP Management Lead }\end{array}$ \\
\hline $\begin{array}{l}\text { Experience with } \\
\text { design }\end{array}$ & $\begin{array}{l}\text { Design integration is recent. } \\
\text { The company redefined } \\
\text { and optimized its processes } \\
\text { and services based on its } \\
\text { own design methods. It } \\
\text { offers design as an added } \\
\text { value to its services. }\end{array}$ & $\begin{array}{l}\text { Design integration is } \\
\text { recent. The company } \\
\text { launched a new service } \\
\text { for the school sector } \\
\text { based on user research } \\
\text { and participatory } \\
\text { design processes. }\end{array}$ & $\begin{array}{l}\text { Design integration is recent. } \\
\text { One team was trained in } \\
\text { design and developed a } \\
\text { new work methodology. } \\
\text { Design was used for the } \\
\text { first time in the redesign of } \\
\text { mortgage services, though } \\
\text { not yet implemented. }\end{array}$ & $\begin{array}{l}\text { Propind outsourced } \\
\text { serviced designers for } \\
\text { guiding a strategic } \\
\text { reflection and the } \\
\text { redesign of strategic IP } \\
\text { management services. }\end{array}$ \\
\hline
\end{tabular}


There were several reasons for choosing those companies for the evaluation of our model. First, the four companies were undergoing design capability development processes when the tests were conducted. Second, the companies were open to participating in the study and sharing sensitive information with the researchers. Third, the researchers were aware of the companies' backgrounds with design, which was helpful for the test facilitation and the interpretation of data. Finally, the combination of two SMEs and two large companies enriched the results. A brief introduction of each participant company is provided below:

- Contcen is a medium-sized company dedicated to providing contact center and customer care solutions. The company was recently introduced to human-centered design by one of its major clients. The latter showed the company a project developed in collaboration with the author's university in which an innovative service concept was developed. The ability to come up with creative and differentiating value propositions through design aroused great interest in Contcen's management. Since then, the company has been working on redesigning and optimizing its processes based on its own design methods, which are now a differentiator of its services.

- FoodCollective is a business group with more than 11,000 employees and is a national leader in industrial catering. It offers catering and cleaning services for schools, nursing homes, hospitals, and companies. However, its experience with design is focused on the catering division for schools in the north of Spain. A local competitor surprised FoodCollective with a disruptive design-based value proposition using participatory processes to create new school canteen services. FoodCollective reacted by hiring a designer and external consultants to develop a new service, based on user research and participatory design processes, that would give it a competitive advantage over its competitors. As a result, FoodCollective used design to capture each facility's particular needs and generate tailored dining experiences. Having realized the potential value of design for the company, today FoodCollective remains committed to building design capabilities to continuously improve its innovation processes.

- Bankop is a credit union renowned locally for its customer orientation. Despite its status as a large organization, it is a small player in a sector led by gigantic multinationals. While the company has deemed the customer experience to be a key aspect of its frontline services for years, it has had little presence in internal processes such as innovation. Nevertheless, market demand and competitor moves led Bankop to position customer experience as one of the main goals of its latest strategic plan. The company thus developed its own methodology based on the principles and methods of design for the development of services with a human-centered focus, so as to respond to the current societal needs. A recently formed four-member team, namely the Customer and Service Development team, was trained in human-centered design to take responsibility for implementing the new methodology. The team had already applied it in the design of a new mortgage service, although it is still in the implementation stage.

- Propind is the fourth participating organization, a small consultancy office specializing in industrial property (IP) services. The relationship of the company with design started with the need for differentiating themselves from low-cost competitors. They found the opportunity to add value to their service offering by moving from transactional to relational interactions with clients, to assist them in the strategic management of IP assets. Some Propind members participated in the design of the new strategic IP services, which were led by outsourced designers. Even though the company develops new services sporadically, first-hand experience with the design process generated an awareness of some design methods and tools that Propind could use to capture customer insights, continuously improve their services, and enhance strategic decision-making in their routine work.

The four tests were carried out through a semi-structured interview with each company, following the model itself as an interview guide, as it was designed to be used in this way. The Supplementary Material presents the original prototype of the model, developed 
in the third phase of this research, and the results collected in the interviews in the fourth phase. The tests involved between two and five people in charge of embedding design in their companies and who had participated in the design projects carried out to date (see the positions of the participants in Table 2). All interviews were audio-recorded to facilitate data capture and lasted between one hour and one hour and fifteen minutes each. At the end of the interview, participants were asked about the model's usefulness for identifying the impact of design and establishing an action plan to meet organizational goals through design.

Finally, the results obtained during the interviews were synthesized and the corresponding refinements were added to the model. The positive results verified the usefulness of the model and identified strengths and opportunities for its use in future research and practice.

\section{Design Impact Measurement and Management (DIMM) Model}

DIMM is a model for measuring and managing the impact of design in organizations, aimed at assisting managers in developing an organization's design capabilities. The model connects the different ways in which design impacts the organization-specifically, changes in organizational perception, processes, and culture-with strategic goals and business outcomes. Through a guided reflection on the different forms by which design impacts and drives value to the organization, the model assists an organization to establish an action plan to further develop design capability, according to its maturity level and particular needs.

As explained earlier, the new DIMM model is built on the four levels of design impact identified by Liedtka et al. [47]. Each design impact level is composed of between two and three subsections that seek to reflect on the various ways in which design impacts on the organization, recognize evidence of such impacts and, where possible, compare them with a previous or a desired state.

The literature was reviewed to determine the appropriate metrics and indicators for each level. It is worth explaining that, to make the model more intuitive and practical for non-design-experienced managers, we simplified the language by using the terms "processes" and "culture" to refer to the levels that Liedtka et al. [47] call "conversations" and "mindsets", respectively. Figure 2 indicates the criteria used to choose the metrics, the studies used as a reference, and examples of indicators used at each level of impact.

At the first level, the model seeks to identify the results of design in the organization. It starts with the establishment of objectives that the organization assigns to design, as well as the metrics that can determine the degree of fulfillment of organizational objectives through design (e.g., turnover, market share, project profitability, etc.). Traditional business metrics are adequate for this purpose, so the Balanced Scorecard [56,57] was taken as a reference framework, one that integrates financial, market, internal performance and growth indicators. Some metrics to consider are turnover, market share, customer lifetime value, development costs, profitability per project, or the number of new products. However, it is up to the company to define the specific metrics, depending on the objectives set for design.

The approach of the second level, design perception, is twofold. On the one hand, it takes the Customer Experience [58-62] approach as a reference to establish and evaluate indicators about how external agents perceive the organization. The usual indicators in this field were considered, such as the net promoter score (NPS), customer satisfaction indexes (CSI), recognitions obtained, brand value, etc. On the other hand, the internal perception is identified, inspired by employee satisfaction surveys that evaluate aspects such as the degree of collaboration, participation, motivation, and training [63-67]. Since these indicators are not always within organizations' reach, the model also allows for a subjective assessment of these aspects to avoid overlooking them. 


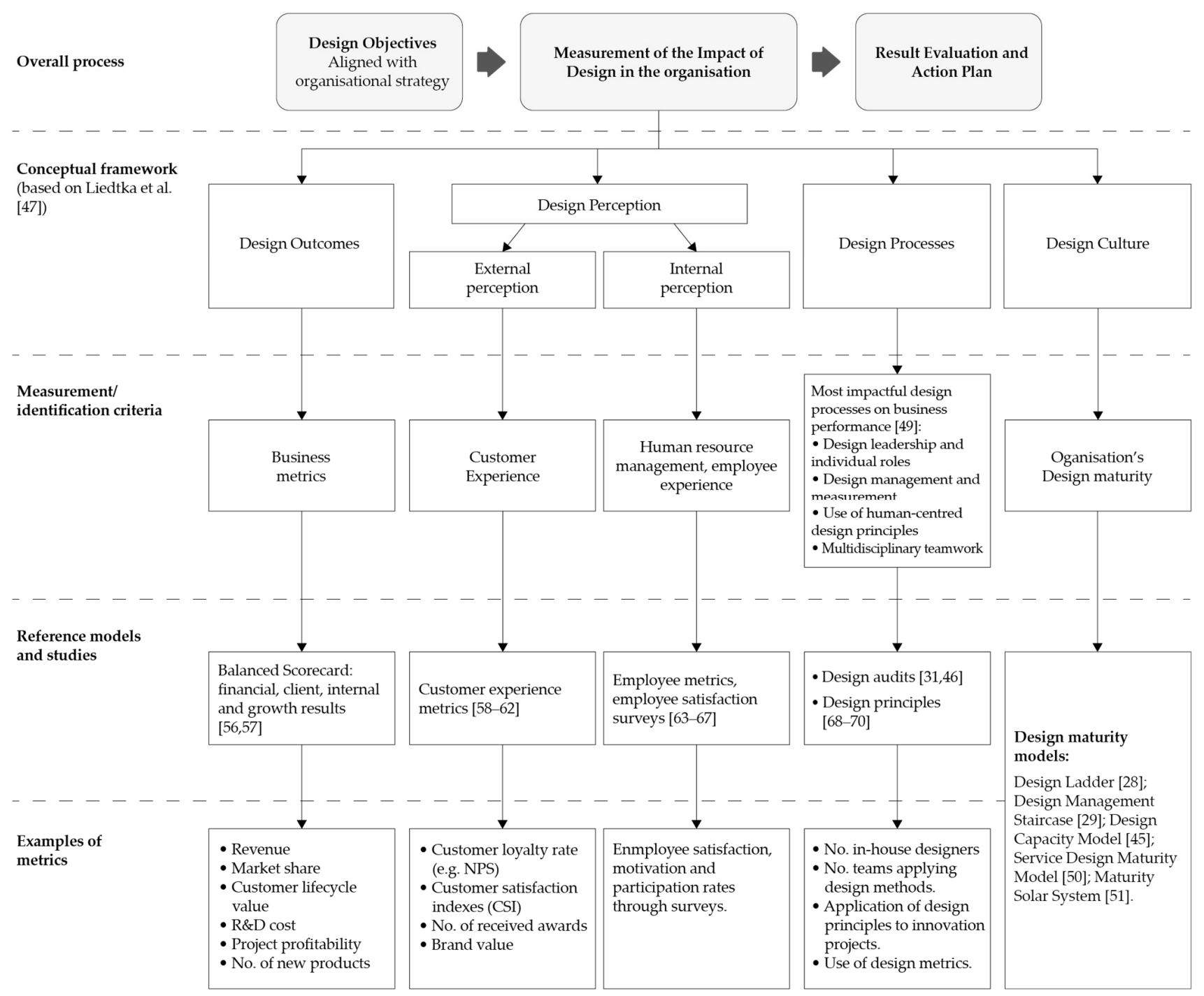

Figure 2. A structured process for the construction of the DIMM model.

At the third level, the identification of the impact of design on internal processes is structured, based on the four design processes with the highest impact for business performance, according to a study by the consultancy firm McKinsey [49]; namely, design leadership and the role of people, design measurement and management, the application of human-centered design principles, and working in multidisciplinary teams. However, in the model's final structure, the concept of "multidisciplinarity" was integrated into the "design principles" sub-section to preserve clarity and intuitiveness for non-design experts. The main sources for establishing indicators at this level were inspired by design audit tools in general [31,46], and works that delved into design leadership, management and principles in particular [68-70].

Finally, the fourth level is dedicated to the design culture within the organization. This level is assessed through a maturity scale, based on previously cited literature, such as that of Ramlau [28], Westcott et al. [30], and Corsten and Prick [50]. The scale features the following degrees of design maturity: initial, repeated, defined and expanded, managed, and optimized. A questionnaire intuitively positions the organization on its corresponding rung of the ladder, which scenario was chosen for two reasons: (i) it is simple and selfexplanatory, so it can be understood by non-design experts; and (ii) like this study, its focus is on developing the organization's design capability. In addition to the organization identifying its degree of design maturity, the purpose of the model at this level is to motivate reflection, establish a vision and propose actions to achieve that desired state. 
Therefore, the model concludes with the establishment of an action plan, with specific measures to achieve the objectives previously assigned to design, considering the results obtained at the different levels of design impact and the relationship between them.

Figure 3 shows the final version of the DIMM model, including the refinements added after testing it with the four organizations. The purpose and differential value of the model compared to previous proposals for measuring design lies in the connection between "soft" metrics related to perception, processes and design culture, and business outcomes that allow the impact of design to be related to organizational goals. In this way, the model provides a comprehensive understanding of the different ways in which design impacts the organization and business strategy.

The model is aimed at companies with different degrees of design maturity. To use the model, one must answer the questions included in each level, indicating metrics (if available) or other evidence to justify the responses. Numeric scales are frequent in models that evaluate design aspects $[46,71,72]$ because they facilitate the fulfillment of the questions. Following previous models, the DIMM model also includes a 1-to-5 valuation scale to support the assessments of the design perception and design processes, and a yes-or-no answering system to simplify the assessment of the design culture.

Although the model can be used individually, teamwork could enrich the information captured and the reflection exercise for creating the action plan. It should be noted that the model should not be treated as a questionnaire but as a structured method to reflect on the different ways in which design impacts the organization. For that reason, in the event that exact information is not available to answer the questions, the manager's own estimates may be used to fulfill the model and enrich the reflection.

Finally, the model is not only intended to provide a snapshot of an organization's current level of design maturity but is also a management tool that companies can use longitudinally. For that reason, it begins with the establishment of specific objectives for design and ends with an action plan in which the organization must set specific measures to strengthen the integration and strategic value of design. Through repeated use of the tool, managers will be able to identify progress in the integration of design, assess the degree to which objectives are being achieved and, therefore, redirect their action plan.

Level 1. Design Results

\subsection{Design Objectives *}

What organizational goals do we aim to address through design? Assess financial, market, internal and/or growth objectives.
1.2. Results Measurement *

What metrics can be used to measure the objectives set and what results do they show?

Assess financial, market, internal and/or growth metrics.

\section{Metric 1:}

E.g.: Market share

Metric 2:

Metric 3:

Metric 4:

Objective 4:

* The number of objectives and metrics to be established is not determined.

Figure 3. Cont. 


\section{Level 2. Design Perception}

\subsection{External perception}

How is our organization perceived by clients and other external stakeholders?

\section{Satisfaction:}

Our clients are satisfied with our products and services.

\section{Relationship:}

The relationship with our clients is excellent.

Loyalty:

We are our client's first choice for solving their current and future needs.

Brand:

Our brand enjoys an esteemed reputation and is renowned in its market niche.

\section{Recognition:}

Our organization received awards, recognitions, mentions, etc. as a result of its

design processes or other reasons.

\subsection{Internal perception}

How do people within the organization perceive design?

\section{Collaboration:}

Collaboration and communication between internal teams is fluid. Design processes foster internal collaboration at individual, team and departmental levels.

\section{Participation:}

Staff members participate in decision-making and propose ideas for improvement. Design enables internal participatory processes.

\section{Motivation:}

Staff members are motivated and committed to organizational goals.

\section{Knowledge:}

Staff members acknowledge the potential of design to generate value for the organization.

\section{Influence:}

Design plays an important role in the organization and supports managerial decision-making.

\begin{tabular}{|c|c|c|c|c|c|}
\hline $\begin{array}{l}\text { Relevant notes, evidence and/or } \\
\text { metrics (if any) }\end{array}$ & \multicolumn{5}{|c|}{$\begin{array}{c}\text { Valuation } \\
1 \text { strongly disagree; } \\
2 \text { disagree; } 3 \text { unable to judge; } \\
4 \text { agree; } 5 \text { strongly agree } \\
\end{array}$} \\
\hline \multirow[t]{5}{*}{ Eg. CSI score $=78$} & 1 & 2 & 3 & 4 & 5 \\
\hline & 1 & 2 & 3 & 4 & \\
\hline & 1 & 2 & 3 & 4 & \\
\hline & 1 & 2 & 3 & 4 & \\
\hline & 1 & 2 & 3 & 4 & \\
\hline $\begin{array}{l}\text { Relevant notes, evidence and/or } \\
\text { metrics (if any) }\end{array}$ & \multicolumn{5}{|c|}{$\begin{array}{c}\text { Valuation } \\
1 \text { strongly disagree; } \\
2 \text { disagree; } 3 \text { unable to judge; } \\
4 \text { agree; } 5 \text { strongly agree }\end{array}$} \\
\hline \multirow[t]{5}{*}{$\begin{array}{c}\text { E.g., } 82 \% \text { in this item in the satisfaction } \\
\text { questionnaire }\end{array}$} & 1 & 2 & 3 & 4 & \\
\hline & 1 & 2 & 3 & 4 & \\
\hline & 1 & 2 & 3 & 4 & \\
\hline & 1 & 2 & 3 & 4 & \\
\hline & 1 & 2 & 3 & 4 & \\
\hline
\end{tabular}

\section{Level 3. Design Processes}

\subsection{Design Leadership and Individual Roles}

The responsibility for leading design processes within the organization is well defined.

An expert team/individual is in charge of disseminating design knowledge throughout the organization and assisting colleagues in design practice.

The management is committed to design and involved with design practice.

Design is pervasive in the organization.

Staff members are trained to put design methods and tools into practice properly.

\subsection{Design Management and Measurement Aspects}

The design function is assigned specific objectives.

Metrics are used to manage the processes and impact of design in the organization.

Design processes and tools are structured and carried out systematically.

\section{Relevant notes, evidence and/or} metrics (if any)

E.g., "No one in the organization has the formal responsibility to account for design".

\begin{tabular}{c|c|c|c|c|c|c|}
$\begin{array}{c}\text { design". } \\
\text { metrics (if any) }\end{array}$ & 1 & 2 & 3 & 4 & 5 \\
\hline $\begin{array}{c}\text { Relevant notes, evidence and/or } \\
\text { mermat }\end{array}$ & 1 & 2 & 3 & 4 & 5 \\
\hline & 1 & 2 & 3 & 4 & 5 \\
\hline & 1 & 2 & 3 & 4 & 5 \\
\hline & 1 & 2 & 3 & 4 & 5 \\
\hline
\end{tabular}

Figure 3. Cont. 


\begin{tabular}{|c|c|c|c|c|c|c|c|c|c|c|}
\hline \multicolumn{3}{|c|}{$\begin{array}{l}\text { Convenient resources are dedicated to carrying out design processes } \\
\text { successfully. }\end{array}$} & & & & 1 & 2 & 3 & 4 & 5 \\
\hline \multicolumn{3}{|c|}{$\begin{array}{l}\text { Convenient spaces are available to carry out design processes properly (e.g., } \\
\text { participatory sessions, visualization tools, prototyping, etc.). }\end{array}$} & & & & 1 & 2 & 3 & 4 & 5 \\
\hline \multicolumn{3}{|c|}{$\begin{array}{l}\text { We have the capacity to involve experts from outside the organization to assist } \\
\text { us in the implementation of design. }\end{array}$} & & & & 1 & 2 & 3 & 4 & 5 \\
\hline \multicolumn{3}{|c|}{$\begin{array}{l}\text { We have the capacity to absorb external design knowledge and we have active } \\
\text { mechanisms to do so. }\end{array}$} & & & & 1 & 2 & 3 & 4 & 5 \\
\hline \multicolumn{3}{|l|}{ 3.3. Design Principles } & & $\begin{array}{l}\text { Relevant notes, evidence an } \\
\text { metrics (if any) }\end{array}$ & & \multicolumn{5}{|c|}{ Valuation } \\
\hline \multicolumn{3}{|c|}{$\begin{array}{l}\text { Human-centered: The generation of value propositions is based on the } \\
\text { identification of users' needs. }\end{array}$} & & & & 1 & 2 & 3 & 4 & 5 \\
\hline \multicolumn{3}{|c|}{$\begin{array}{l}\text { Visualize emotions and experiences: We use visualization tools (e.g., Personas, } \\
\text { Customer Journey Map, Service Blueprint, etc.) throughout design processes to } \\
\text { support understanding, empathizing, creating and communicating practices. }\end{array}$} & & & & 1 & 2 & 3 & 4 & 5 \\
\hline \multicolumn{3}{|c|}{$\begin{array}{l}\text { Prototype products and services: We employ prototyping techniques to evaluate } \\
\text { different ideas and strategies. }\end{array}$} & & & & 1 & 2 & 3 & 4 & 5 \\
\hline \multicolumn{3}{|c|}{$\begin{array}{l}\text { Fail early, learn fast: Our processes are iterative, and we embrace uncertainty } \\
\text { and controlled risks. }\end{array}$} & & & & 1 & 2 & 3 & 4 & 5 \\
\hline \multicolumn{3}{|c|}{$\begin{array}{l}\text { Multidisciplinarity: To support developmental work and strategy development, } \\
\text { we integrate knowledge from different disciplines and engage members from } \\
\text { different areas of the organization. }\end{array}$} & & & & 1 & 2 & 3 & 4 & 5 \\
\hline \multicolumn{11}{|c|}{ Stakeholder engagement: How do we integrate users and other stakeholders in our processes according to the following participation roles? } \\
\hline $\begin{array}{l}\text { 1. Indirect participant: } \\
\text { Users/stakeholders are } \\
\text { considered without the } \\
\text { need for their } \\
\text { participation. }\end{array}$ & $\begin{array}{l}\text { 2. Informant: } \\
\text { Users/stakeholders share } \\
\text { their knowledge about } \\
\text { their habits, experience, } \\
\text { concerns, etc. }\end{array}$ & \multicolumn{2}{|c|}{$\begin{array}{l}\text { 3. Evaluator: } \\
\text { Users/stakeholders adopt } \\
\text { a critical attitude towards } \\
\text { a product or service in } \\
\text { search of opportunities to } \\
\text { improve it. }\end{array}$} & $\begin{array}{l}\text { 4. Creator: } \\
\text { Users/stakeholders } \\
\text { identify problems and/or } \\
\text { propose opportunities } \\
\text { and solutions. }\end{array}$ & \multicolumn{5}{|c|}{$\begin{array}{l}\text { 5. Developer: } \\
\text { Users/stakeholders are } \\
\text { integrated into the } \\
\text { project team. }\end{array}$} & \\
\hline
\end{tabular}

\section{Level 4. Design Culture}

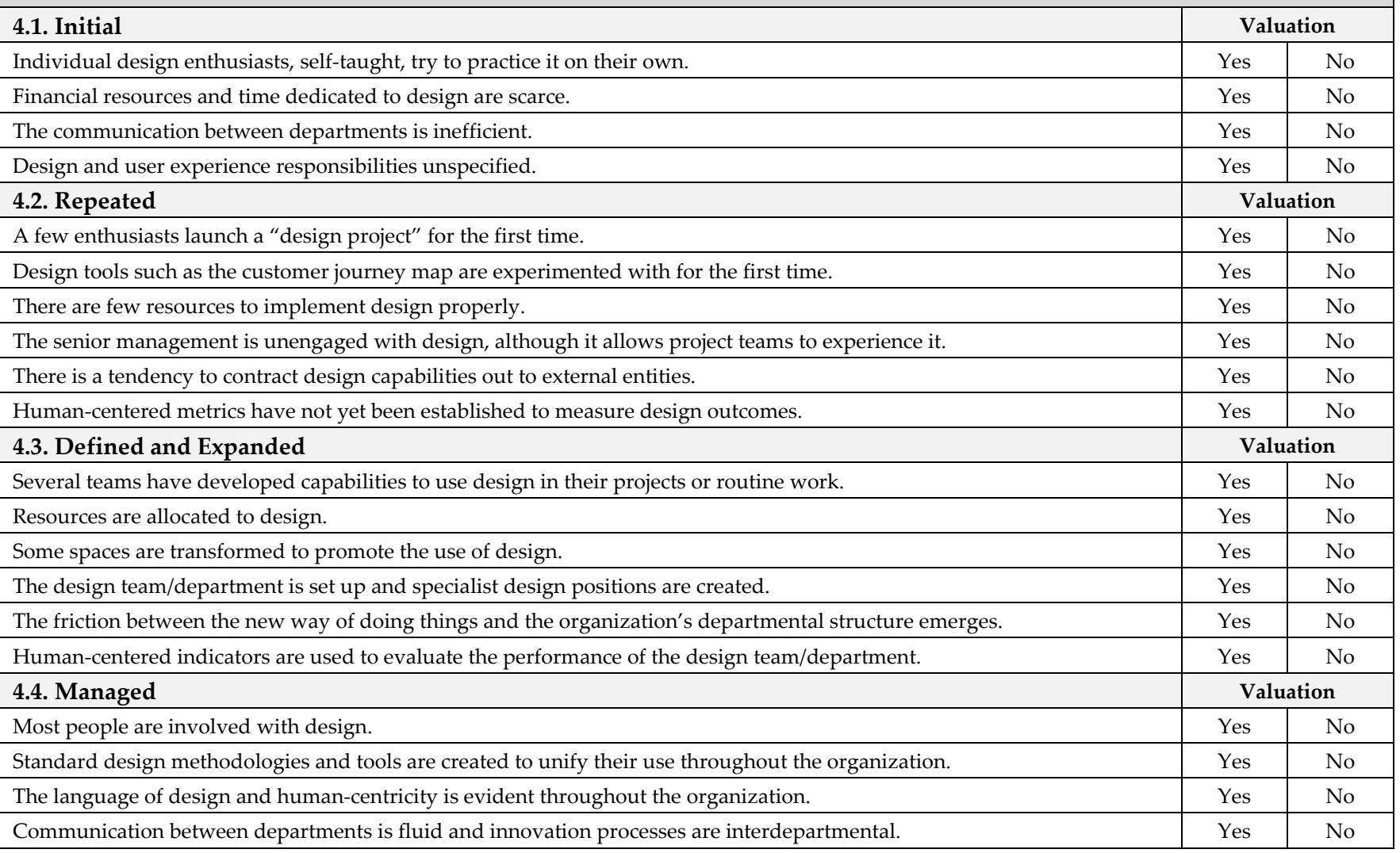

Figure 3. Cont. 


\begin{tabular}{|c|c|c|c|c|c|c|}
\hline \multicolumn{5}{|c|}{ The use of human-centered indicators is widespread throughout the organization. } & Yes & No \\
\hline \multicolumn{5}{|c|}{ 4.5. Optimized } & \multicolumn{2}{|c|}{ Valuation } \\
\hline \multicolumn{5}{|c|}{ The whole organization is involved with design. } & Yes & No \\
\hline \multicolumn{5}{|c|}{$\begin{array}{l}\text { The design methodology becomes flexible and experimentation with new tools is encouraged, which gives rise to the } \\
\text { continuous learning and adaptation of design methods to new needs. }\end{array}$} & Yes & No \\
\hline \multicolumn{5}{|c|}{ The organizational structure encourages the co-creation of service experiences in multidisciplinary teams. } & Yes & No \\
\hline \multicolumn{5}{|c|}{ All initiatives are tied to human-centered indicators and deliverables. } & Yes & No \\
\hline \multicolumn{7}{|c|}{ Result: } \\
\hline \multirow{5}{*}{ Initial } & \multicolumn{5}{|c|}{ Optimized } & \\
\hline & \multirow[b]{3}{*}{ Repeated } & Defined and & Managed & \multirow{5}{*}{\multicolumn{2}{|c|}{$\begin{array}{l}\text { Design leads the } \\
\text { organization and is } \\
\text { ingrained in its culture. }\end{array}$}} & \\
\hline & & Expanded & Design influences & & & \\
\hline & & Design expands & business strategy. & & & \\
\hline & \multirow{2}{*}{$\begin{array}{l}\text { The first design success } \\
\text { stories emerge. }\end{array}$} & throughout the & & & & \\
\hline $\begin{array}{l}\text { The first design } \\
\text { initiatives emerge. }\end{array}$ & & & & & & \\
\hline \multicolumn{7}{|c|}{ Action Plan } \\
\hline \multicolumn{7}{|c|}{ What actions should we take to develop our capabilities and get more out of design? } \\
\hline \multicolumn{7}{|l|}{ Action 1: } \\
\hline \multicolumn{7}{|l|}{ Action 2: } \\
\hline \multicolumn{7}{|l|}{ Action 3: } \\
\hline
\end{tabular}

Figure 3. Design Impact Measurement and Management (DIMM) model.

\section{Experimentation with the Model}

This section summarizes the results obtained during the interviews conducted with the four participant companies to measure the impact of design using the DIMM model. By participating in this research, the companies sought to explore the impact of their recent design projects. Although all companies were committed to design, they still showed emerging capabilities by the time they participated in the tests, so they considered collaborating with design researchers as an opportunity to gain design knowledge that they could use in their ongoing and future projects.

\subsection{Contcen}

Contcen discovered, through design, the potential to understand its customers' needs. In collaboration with expert designers, it developed a new service based on user research and prototype design and testing. Since then, the company has not only been recognized for the quality of its contact center and customer care services but also developed the ability to advise and collaborate in the design of tailor-made services for its clients. These improvements were articulated in a new work methodology based on the principles of service design and user experience (UX).

- Design results. Although it was too early to obtain quantifiable results from the integration of design when the test was conducted, the company foresaw benefits in the medium term. They were convinced that the agility they gained in execution times would soon achieve higher profitability per project and they would be able to capture a larger market share. In addition, as the company was proactive in configuring their offer, it revealed to customers their own needs through a prior diagnosis. As a result, it was able to prescribe more comprehensive services that resulted in higher turnover.

- Design perception. The company perceived that customer satisfaction increased, as some clients asserted that they were "impressed" with the new way of working. The company claimed that customer loyalty improved and that the hours spent with customers increased significantly. Internally, participation and collaboration between 
people also increased; "the method itself makes people participate more," as said by the Director of Projects and Technology.

- Design processes. The company hired two people to form a design team. These two people led the design processes, but 11 other people received specific UX training, and an increasing number of employees were getting involved in projects using the new methods. Regarding capturing customer needs, the Director of Projects and Technology explained that "now, much more information is collected". They also progressed in the use of digital prototypes to streamline their processes and minimize development errors. At the same time, they pointed out that they kept improving their working methods and were considering augmenting the use of visualization tools and the integration of end-users in design processes. However, the design team had not yet been assigned specific objectives and performance indicators.

- Design culture. The people interviewed considered that design was defined and expanded in the company. They ensured that everyone was, to some extent, committed to design, as all projects were approached from a design perspective. However, the new culture was recent and not yet consolidated, which created some chaos at work. They felt energized to take on the challenge and were confident that the experience would enable them to become more efficient with the new processes. Specifically, they defined three priority areas for improvement: internal communication, the involvement of end-users, and the redesign of certain deliverables for refining the new work methodology. Furthermore, they were exploring metrics to manage their design processes, to continuously improve their capabilities.

The results showed that the model served to review the impact of design in Contcen. Experimentation itself generated interest in the company, which was considering using quantitative indicators (e.g., execution times or the number of errors) and qualitative indicators (e.g., customer feedback or the type of errors made) to manage its design processes. This is evidence that the model can not only serve as a tool to measure the impact of design in the company but can also trigger a greater awareness of the value of design and encourage its integration.

\subsection{Food Collective}

Recently, FoodCollective developed a new canteen service for schools called "Borbor". Thanks to user research and the participatory design processes, the company was able to propose tailor-made canteen experiences for each center. Generating this service was FoodCollective's first experience with design, but the evaluation carried out through the model to measure the impact of design in the organization showed that it had already undergone permanent changes. The most discernible outcome was the launch of the new service, for which visualization tools and participatory processes were central.

- Design results. Interviewees foresaw improvements in the medium term. Due to the nature of their market, "we are now investing to reap the rewards," the Sales Manager indicated. However, he pointed out that design was helping them to build customer loyalty and that the reception of the new service was good, so they were optimistic about obtaining economic benefits "in one or two years".

- Design perception. The launch of the Borbor service contributed to customers' perception of the company, they said, despite not yet having the annual results of the NPS or loyalty indicators. The new service reflected a more forward-looking working method and encouraged closer collaboration with clients and users. They also pointed out that "the collaboration with the university to develop the new service underpinned the image of the service itself". Besides, they claimed that the people working at FoodCollective were motivated by the new approach and working procedures.

- Design processes. The company decided to hire a designer, as the skills required to deliver the Borbor service were new to FoodCollective. Other people were occasionally involved in the design process but had not received specific design training. They also claimed that "users' active participation increased" in the innovation processes. The 
working methodology around the Borbor service improved with respect to the use of visualization tools and the launch of pilot services. However, the design activity at FoodCollective remained formally unmanaged and located only in the organizational area in charge of the new service.

- Design culture. Respondents considered design in FoodCollective to be "repeated", referring to the scale used in the model to measure design maturity. There was a person dedicated to design processes, and there was a defined method to carry out such processes. They pointed out that the next step required scaling up design within the organization, for example, by hiring or training others to lead design processes, using design in other projects, and establishing design processes at the organizational level. They stressed the need to succeed in existing projects to gain management's backing and to devote more effort and resources to design activities.

In terms of using the model to assess the impact of design, many of the responses were based on perceptions rather than hard data. This is because the company expected business results in the longer term, plus gathering this data required some time. However, it was possible to determine specific metrics to assess design objectives and evaluate all sections of the model, at least qualitatively. Therefore, the model enabled a profound understanding of how design had impacted FoodCollective so far. Furthermore, the Sales Manager indicated that the model helped them visualize the maturity of design in the company. "When you see it in writing it is easier to see where you are and where you need to go," he declared. In other words, in addition to identifying the impact of design on the organization, the model also visualized the previous and next steps for the optimal development of design capability.

\subsection{Bankop}

Bankop members explained that developing capabilities to design excellent customer experiences was at the top of their priorities. This financial entity pursued two interrelated goals for design: to introduce customer knowledge via new service development processes, and to uphold its position as a reliable and customer-oriented firm. The new Customer and Service Development team took the lead for these goals and participated in an in-company design training project, facilitated by researchers from the authors' university. Some staff members had already had some contact with designers, though this time the team expected to develop their design skills as much as to conduct future design projects autonomously.

- Design results. The company regarded the development of customer experience capabilities as a long-term commitment. Therefore, they did not envisage any impact on the market by the time the interview was conducted, and no market indicators could be measured. "If everyone is supporting us [it] is because they know that it will have an impact in the long term, but we don't have the capacity to measure it yet," explained one of the Customer and Service Development Technicians. However, during the training project, the team designed a new mortgage service that was already in the implementation phase, so the effects on the market were expected to become visible soon after.

- Design perception. The services resulting from design projects had not yet been launched onto the market, so the impact of design remained within the organizational boundaries. However, the internal dissemination of results was outstanding and raised organization-wide commitment to design, including among the senior management.

- Design processes. New service development processes underwent significant changes. New organizational structures were formed, including the creation of the new Customer and Service Development team and the recruitment of a designer. In addition, the team developed a working methodology nurtured by human-centered design methods and principles, which they planned to follow systematically in future projects. One of the technicians explained that "this is a new mindset, a methodology and a tool that will be implemented from now on. What we once thought now has form and structure". 
- Design culture. Design practices were incipient, but they had a solid base thanks to the development of the new work methodology and the support of the senior management. The widespread dissemination of early results generated interest in other areas of the organization, so the forthcoming challenge for the Customer and Service Development team was to engage other departments in design projects to scale up design capabilities throughout the organization.

The DIMM model was useful for raising awareness of the organizational change process and identifying good practices to use design effectively, such as establishing synergies with other departments that were showing interest in design, and defining metrics to measure its impact on the market. In short, the model fostered a more mature and widespread design culture throughout the organization.

\subsection{Propind}

Design processes in Propind were facilitated by external designers. As an IP consultancy, design did not play a central role in their routine work. Thus, when asked about the goals for design, the interviewees questioned whether developing in-house design capabilities was a principal objective for the organization. The reason for outsourcing to external designers was that they lacked the capabilities to optimally conduct a strategic reflection themselves and to redesign their most advanced service offerings. However, the takeaways of the design project extended beyond the development of two innovative services, to raising design awareness and developing basic design skills:

- Design results. Propind trusted in design as a method for confirming certain hunches about market needs and responding to them with a differentiating service offering, one that would expand the client base and increase the turnover. Therefore, a direct result of the design project was the launch of two new, advanced IP management services. Although pilot projects were still to be implemented, Propind members were optimistic because they had received positive feedback from their clients and the backing of local business associations. In view of the encouraging results, the company was considering continuing to develop some skills, to improve the capture of market insights and innovation through design methods.

- Design perception. The shift from a transactional to a relational service model was expected to enhance client loyalty. In addition, Propind learned to use design research methods (e.g., conducting semi-structured interviews and synthesizing insights into customer personas) to get closer to customers, understand their needs and reduce the gap between customer expectations and the service provided. Internally, they also incorporated visualization tools that supported team communication and decision-making.

- Design processes. Propind members who participated in the design project developed basic design skills and learned methods to improve team decision-making, customer orientation and visual thinking. However, the capacities acquired so far were not considered sufficient to address design projects autonomously. If Propind launched a new design project, it would need the assistance of external designers again to carry out those processes requiring more advanced design capabilities.

- Design culture. Design was nascent at Propind. That first interaction with design caused Propind to understand how design brought value to their business. As design was not central to the organization's routine work, its design maturity was expected to grow slowly. Nevertheless, the company was open to developing some progress in design methods-e.g., facilitating co-creation workshops with clients and capturing and visualizing customer needs. "Emotional aspects are key in a multitude of circumstances, so we will certainly use these tools in future activities", the Managing Director indicated.

The DIMM model showed Propind that, beyond the development of new services, design also influenced the capabilities and work dynamics of the project team. The model 
created a space for the team to reflect on the value of design and identify how it enabled placing the client at the center of decision-making processes.

\section{Critical Evaluation of the Model}

Our experimentation with the DIMM model showed promising results. In this section, we identify and critically discuss the key insights captured from the test sessions, to explain the differential value of the model over previous propositions in the literature. The limitations of the study are also discussed, to point out future research directions.

First, in line with this Special Issue, the tests using the DIMM model showed that all four participant organizations incorporated human-centered capabilities that enabled them to address complex and uncertain projects in their particular business contexts. In addition, the cases unveiled contributions to the EU's Sustainable Development Goals. Firstly, Contcen, FoodCollective and Bankop hired in-house designers, thus promoting the generation of decent employment. Secondly, the four organizations innovated their service offering through design. What is more, design promoted the competitiveness of the organizations through developing their innovation capabilities. Thirdly, the universitybusiness collaboration paved the way for future projects concerning economic growth and innovation.

However, the tests also showed the inexperience of the organizations in managing their design capabilities. Therefore, when the participants were asked about the DIMM model after the interviews, they highlighted that it helped them broaden their understanding of design and its organization-wide implications. It enabled them to connect internal design activities to business results and revealed the need to devise a formal strategy for design.

The model proved flexible to the conditions of each participating company with respect to its size, sector and the perspective from which the company approached design-i.e., user experience, customer experience, participatory design, or strategic design. It also adapted to the information in the interviewees' possession at the time the tests were conducted. The four companies managed to complete all the steps of the model, even though their design capabilities were merely incipient.

Despite the fact that the general structure and contents of the model were successful, the tests revealed opportunities for refinement. For instance, the original version of the model did not include the legend indicating the meanings of the 1-to-5 rating scale used in the "design perception" and "design process" levels. A box was also included for each assessable item, to note any relevant comments, evidence or metrics that supported the numeric assessment. In addition, the questions that the interviewees did not interpret as expected were reformulated to facilitate their comprehension. As explained before, these refinements are already added to the last version of the model, presented in Figure 3.

Based on the test results and the feedback gathered about the model, we distinguished three ways in which it contributed to the participating organizations: as an assessment tool, as a reflective tool, and as a strategizing tool. These three contributions are discussed below.

\subsection{The DIMM Model as an Assessment Tool}

One of the principal purposes of the DIMM model is to provide an evaluation of design's impact on the organization. Compared to previous models, DIMM demonstrated the advantage of offering a multilevel understanding of the firm's design capability. The participants highlighted the importance of gathering a holistic understanding of the implications of design in one single snapshot of the firm, and their relationship with business results.

The four levels of the model provided relevant data for identifying the impact of design. Despite much of the information captured being qualitative, a body of objective evidence reinforced the robustness of the results-e.g., implementing new services, engaging new clients, or developing an in-house design team. It is noteworthy that it was not possible to measure the financial impact of design in any of the four companies as yet. The companies also reported difficulties in quantifying changes in external and internal perceptions. First, this was because, by the time the tests were conducted, the companies 
barely had time to carry out quantitative measurements. Second, this was because the companies did not expect to sense an immediate reaction in the market, especially those that had not as yet officially implemented their new services.

The model's capacity to represent an accurate and objective description of the different aspects of the design capability of an organization might be questioned due to the use of qualitative data. However, the model was not intended to provide exact measurements but rather a series of observations that together explained the impact of design on the organization holistically, in order to identify gaps and make agile decisions. Thus, one remarkable aspect of the DIMM model is its capacity to adapt to the knowledge resources available to the organization during the evaluation.

Nevertheless, we advocate that organizations that are experienced in design should track the market results of design-related activities for optimal usage of the model. For example, FoodCollective and Bankop asserted they did not foresee problems in incorporating metrics, such as financial results, customer satisfaction indexes (CSI) and net promoter score (NPS), in future iterations with the model since they already gathered this data periodically.

\subsection{The DIMM Model as a Reflective Tool}

Beyond offering a static picture of the impact of design on the organization at a given moment, the DIMM model encouraged a guided reflection on how design drove value to the organization in its particular business context. Provided that design awareness is one of the pillars of design capability, reflective thinking helped the participating organizations advance their design capability.

The test participants considered conversing about the impact of design to be atypical. None of them had ever discussed how to manage their design capabilities before conducting the tests, simply because they did not have any specific forum for it among their routine activities. The DIMM model provided a space for thinking of design aspects that were uncommon for the participants, e.g., application of design principles, escalation of design capabilities, measurement of design results, etc. The group-interview approach favored the discussion, and the multilevel structure of the model enriched the reflection. As a result, the DIMM model served to bring to the surface the tacit knowledge of the participants about design, making them more conscious of its impact, the organization's strengths, and the opportunities for improvement.

The experiments also demonstrated that the DIMM model enhanced learning. Participants highlighted several "revelations" [26] to improve the performance of their design capabilities. For example, Contcen members realized that they rarely engaged end-users (i.e., the client of the client) during their co-design activities, which hindered their capacity to sense market needs. For Propind, the revelation was that user-research processes that were used during design projects could also enhance their routine relational activities with their customers. Participants from FoodCollective concluded that the sustainability of their capabilities to carry out participatory design processes was endangered because they over-relied on the in-house designer. In summary, the DIMM model helped the organizations explore and learn about the contribution of human-centered design capabilities to improving project performance and management in their particular business contexts.

\subsection{The DIMM Model as a Strategizing Tool}

The value of design for addressing uncertain and complex challenges is best seen when it takes a strategic position in the organization and is part of the institutional culture [34]. However, before conducting the tests, none of the participating organizations had a formal plan to develop design capability. Decisions about developing design capabilities were often opportunistic and short-term, such as attending design events and participating in funded design projects. The DIMM model supported the decision-making of the participating organizations for elevating the role of design because it enabled understanding the impact of design on the organization holistically, it uncovered the tacit knowledge of 
interviewees through reflective thinking, and the structure of the model itself guided the definition of objectives and improvement actions to develop design capability. In addition, some participants valued positioning their organization on a maturity scale, to determine their next steps for developing design capability.

Therefore, one of the main differences of DIMM compared to other models is that the definition of objectives for design and the formulation of an action plan are intrinsic to the evaluation procedure. During the test sessions, the questions of the tool themselves reminded the participants of key aspects of design capability and, consequently, facilitated the identification of capability gaps on which to take action. In addition, the model requested that participants verbalize their personal ideas, which fostered a clear definition and shared understanding of design goals with the rest of the interviewees. Although the model would not provide specific procedures to establish goals and strategies, none of the participating companies needed additional help. Even so, the model is open to complementary techniques that could nurture strategic reflection and thus improve decision-making.

The DIMM model succeeded in developing a clear vision for design in each organization, even though they pursued considerably different goals. FoodCollective expressed a willingness to extend the design methodology to other areas of the organization, although the design function itself was not yet consolidated. The company was awaiting success stories with the new service that would help them reveal the value of design throughout the organization and find internal allies. Propind was also interested in the impact that their new services had on the market. In contrast, Contcen and Bankop formed expert teams to take charge of design in future strategic projects. Contcen planned several lines of action to continue developing design capabilities related to internal communication, end-user involvement, and the establishment of metrics for design management. Bankop was aware that they needed to embed human-centric tools in their internal processes, so they established the single and clear target of replicating the design methodology in new projects.

Naturally, the capacity of the DIMM model to assist companies in strategic decisionmaking is subject to the position that the users hold in their organizations. The hierarchical differences influencing the power to make strategic choices became evident during the experiments. Although the participants reported that they were satisfied with the test results, they doubted that they would use the model without the guidance of an expert. They did not feel confident enough to use the model themselves, or they considered that their organizations' design culture was not mature enough to use specific models to manage design. They asserted that they would stick with their habitual management approaches and seize their occasional collaborations with researchers to build spaces to reflect on the future of design in their organizations. In any case, the experimentations with the DIMM model were an excellent opportunity for the organizations to develop a formal plan for developing their design capabilities.

\subsection{Limitations and Future Research}

The DIMM model and the research setup presented some limitations that point the way for future research opportunities.

First, the results showed that the functionality of the model was conditioned by the quantity and quality of design-related information available to the organization when the interviews were conducted. On future occasions, supplementary data collection methods could optimize the use of the model and provide deeper insight into certain items. Even so, by using estimates at points where no previous data was available, the model succeeded in assisting organizations in understanding the impact of design, reflecting on the contribution of design to the organization, and improving the decision-making on design management aspects. In addition, since the experiments were guided by two design researchers who were already familiar with the model, it is unclear to what extent non-design experts could take advantage of the model without a facilitator. Organizations might need additional guidelines for using the model autonomously. 
On the other hand, the model is not intended to be used to compare the level of design integration between companies quantitatively. The results of any comparison between cases would be questionable because of the impossibility of measuring the integration of design in the organization with rigorous quantitative criteria. The purpose of the model is just the reverse: to fit the context and needs of each organization in order to gain a deep understanding of the impact of design and how to leverage its potential benefits. Nevertheless, qualitative comparisons between cases could prove insightful, especially if they are aimed at identifying key lessons for other companies to devise effective strategies for developing design capability. The model's value is not to provide a clinically precise measurement of design impact but to assist managers in decision-making through the combination of available data, including their tacit knowledge.

As for the research method, a larger number of case studies should be evaluated to demonstrate the usefulness of the model in companies with diverse characteristics. The four organizations participating in this study displayed a similar level of design maturity: although they had already begun to dedicate resources to design and to institutionalize design practices, the integration of design was still in its infancy. Thus, it is unknown whether the model is helpful for companies with no previous experience with design or companies with greater design maturity.

Besides, each participating company only used the DIMM model once. Therefore, it was not possible to track whether the decisions made during the tests materialized later into actions. Using the model periodically (e.g., annually) could show the evolution of design in the organization. Longitudinal studies are thus needed to demonstrate the long-term usefulness of the model.

The implications of the DIMM model are not limited to assisting organizations in design integration. Still, they can also support future research in this area, as it has proven useful in gaining a holistic understanding of the impact of design on the organization. The potential applications of the model for scientific research are diverse and, with some adaptations, would make it possible to analyze the impact of design in companies, comparing it by sector, type of company or geographical location; study the process of integration of design in companies; study the maturity of design in companies; or discover the objectives, expectations, and vision of companies for design.

\section{Conclusions}

Based on the necessity of organizations to incorporate human-centered capabilities in project management, to enhance decision-making in complex and uncertain contexts [5,7], and the growing interest in integrating design as a capability to meet current business and societal demands sustainably [73-75], this article presented and critically evaluated a model to assist organizations in developing their design capabilities. The DIMM model assesses how design impacts the organization, in order to guide a reflection on how to orient the design function toward the fulfillment of strategic objectives.

The model was successfully tested with four organizations. Through experimenting with the model, the companies recognized the potential of design to enhance their project management practices, as well as their design maturity and identified the next steps to further leverage design as a source of differentiation and competitive advantage. Moreover, the four companies unveiled the contributions of design to the EU's Sustainable Development Goals on decent work, innovation and strategic partnerships. Thus, this research contributes to an emerging stream in the field of project management integrating human-centered capabilities in decision-making processes. The DIMM model supports the development of design capability, to endow organizations with the competence to address complex and uncertain challenges.

The DIMM model contributes an action-oriented design management tool that connects the impact of design on different levels of the organization, including business results, perception, processes and organizational culture. Furthermore, the model demonstrated to be more than an assessment framework; it is a reflective tool that assists organizations 
in managerial decisions concerning the use of design and the development of design capability. It is a model built on the strengths of previous design assessment models in the literature, with the difference that it approaches design impact from multiple levels and proposes a procedure that guides decision-making. Finally, future research directions were proposed to explore different uses of the model in new contexts and over longer periods.

Supplementary Materials: The following are available online at https:/ / www.mdpi.com/article/10 .3390 / su132212580/s1, Table S1: Results of the experimentations with the DIMM model.

Author Contributions: All of the authors contributed significantly to the writing of the paper: conceptualization, I.L. and I.I.; methodology, I.L., I.I. and D.J.-L.; investigation, I.L. and I.I.; data curation, I.L.; writing — original draft preparation, I.L. and I.I.; writing-review and editing, I.L., I.I., M.H. and D.J.-L.; visualization, I.L., I.I. and D.J.-L.; supervision, M.H. and D.J.-L.; project administration, I.I.; funding acquisition, I.L. and I.I. All authors have read and agreed to the published version of the manuscript.

Funding: This research was funded by the Program to promote the generation of opportunities, differential value and sustainability of the business fabric of Gipuzkoa, Annex VI: Valorization of the creative economy, awarded by the Economic Promotion, Tourism and Rural Areas Department of the Gipuzkoa Provincial Council, grant code EKONOMIA SORTZAILEA-15.

Institutional Review Board Statement: The study was approved by the Research Ethics Committee of Mondragon Unibertsitatea (Reference No. IEB-20211102, date of approval: 2 November 2021).

Informed Consent Statement: Informed consent was obtained from all subjects involved in the study.

Data Availability Statement: Not applicable.

Conflicts of Interest: The authors declare no conflict of interest. The funders had no role in the design of the study; in the collection, analyses, or interpretation of data; in the writing of the manuscript, or in the decision to publish the results.

\section{References}

1. Moore, M.L.; Tjornbo, O.; Enfors, E.; Knapp, C.; Hodbod, J.; Baggio, J.A.; Norström, A.; Olsson, P.; Biggs, D. Studying the complexity of change: Toward an analytical framework for understanding deliberate social-ecological transformations. Ecol. Soc. 2014, 19, 54. [CrossRef]

2. Sullivan, K.; Thomas, S.; Rosano, M. Using industrial ecology and strategic management concepts to pursue the Sustainable Development Goals. J. Clean. Prod. 2018, 174, 237-246. [CrossRef]

3. Saynisch, M. Mastering Complexity and Changes in Projects, Economy, and Society via Project Management Second Order (PM-2). Proj. Manag. J. 2010, 41, 4-20. [CrossRef]

4. Brady, T.; Davies, A.; Nightingale, P. Dealing with uncertainty in complex projects: Revisiting Klein and Meckling. Int. J. Manag. Proj. Bus. 2012, 5, 718-736. [CrossRef]

5. Morris, P.W.G. Reconstructing Project Management; Wiley: New York, NY, USA, 2013; Volume 7, ISBN 9780470659076.

6. Hölzle, K.; Rhinow, H. The Dilemmas of Design Thinking in Innovation Projects. Proj. Manag. J. 2019, 50, 418-430. [CrossRef]

7. Mahmoud-Jouini, S.B.; Midler, C.; Silberzahn, P. Contributions of Design Thinking to Project Management in an Innovation Context. Proj. Manag. J. 2016, 47, 144-156. [CrossRef]

8. Dunne, D.; Martin, R.L. Design Thinking and How It Will Change Management Education: An Interview and Discussion. Acad. Manag. Learn. Educ. 2006, 5, 512-523. [CrossRef]

9. Cousins, B. Design thinking: Organizational learning in VUCA environments. Acad. Strateg. Manag. J. 2018, 17, 1-18.

10. Grenha Teixeira, J.; Patrício, L.; Huang, K.H.; Fisk, R.P.; Nóbrega, L.; Constantine, L. The MINDS Method: Integrating Management and Interaction Design Perspectives for Service Design. J. Serv. Res. 2017, 20, 240-258. [CrossRef]

11. Lockwood, T. Design Thinking: Integrating Innovation, Customer Experience, and Brand Value; Allworth Press: New York, NY, USA, 2010; ISBN 978-1-58115-668-3.

12. Costa, N.; Patrício, L.; Morelli, N.; Magee, C.L. Bringing Service Design to manufacturing companies: Integrating PSS and Service Design approaches. Des. Stud. 2018, 55, 112-145. [CrossRef]

13. Gloppen, J.; Fjuk, A.; Clatworthy, S. The role of service design leadership in creating added customer value. In Innovating for Trust; Lüders, M., Andreassen, T.W., Clatworthy, S., Hillestad, T., Eds.; Edward Elgar Publishing: Cheltenham, UK; Northhampton, UK, 2017; pp. 230-244.

14. Iriarte, I.; Hoveskog, M.; Justel, D.; Val, E.; Halila, F. Service design visualization tools for supporting servitization in a machine tool manufacturer. Ind. Mark. Manag. 2018, 71, 189-202. [CrossRef]

15. Morelli, N.; Götzen, A.; de Simeone, L. Service Design Capabilities; Springer: Cham, Switzerland, 2021; ISBN 978-3-030-56281-6. 
16. Yu, E.; Sangiorgi, D. Service Design as an Approach to Implement the Value Cocreation Perspective in New Service Development. J. Serv. Res. 2017, 21, 40-58. [CrossRef]

17. de Bont, C.; Xihui Liu, S. Breakthrough Innovation through Design Education: Perspectives of Design-Led Innovators. Des. Issues 2017, 29, 1-5. [CrossRef]

18. Dunne, D. Implementing design thinking in organizations: An exploratory study. J. Organ. Des. 2018, 7, 16. [CrossRef]

19. Ostrom, A.L.; Bitner, M.J.; Brown, S.W.; Burkhard, K.A.; Goul, M.; Smith-Daniels, V.; Demirkan, H.; Rabinovich, E. Moving forward and making a difference: Research priorities for the science of service. J. Serv. Res. 2010, 13, 4-36. [CrossRef]

20. Elsbach, K.D.; Stigliani, I. Design Thinking and Organizational Culture: A Review and Framework for Future Research. J. Manag. 2018, 44, 2274-2306. [CrossRef]

21. Henn, R. Aftermarkets the Messy Yet Refined Logic of Design. J. Corp. Citizsh. 2010, 37, 41-55.

22. Price, R.; Wrigley, C.; Matthews, J. Action researcher to design innovation catalyst: Building design capability from within. Action Res. 2018, 19, 318-337. [CrossRef]

23. Martinkenaite, I.; Breunig, K.J.; Fjuk, A. Capable Design or Designing Capabilities? An Exploration of Service Design as An Emerging Organizational Capability in Telenor. J. Entrep. Manag. Innov. 2017, 13, 69-87. [CrossRef]

24. Mutanen, U.M. Developing organisational design capability in a Finland-based engineering corporation: The case of Metso. Des. Stud. 2008, 29, 500-520. [CrossRef]

25. Aricò, M. Service Design as a Transformative Force: Introduction and Adoption in an Organizational Context. Ph.D. Thesis, Copenhagen Business School, Frederiksberg, Denmark, 2018.

26. Kurtmollaiev, S.; Fjuk, A.; Pedersen, P.E.; Clatworthy, S.; Kvale, K. Organizational Transformation Through Service Design: The Institutional Logics Perspective. J. Serv. Res. 2018, 21, 59-74. [CrossRef]

27. Landoni, P.; Dell'Era, C.; Ferraloro, G.; Peradotto, M.; Karlsson, H.; Verganti, R. Design Contribution to the Competitive Performance of SMEs: The Role of Design Innovation Capabilities. Creat. Innov. Manag. 2016, 25, 484-499. [CrossRef]

28. Ramlau, U.H. In Denmark, Design Tops the Agenda. Des. Manag. Rev. 2004, 15, 48-54. [CrossRef]

29. Kootstra, G.L. The Incorporation of Design Management in Today's Business Practices. An Analysis of Design Management Practices; Inholland University of Applied Sciences: Rotterdam, The Netherlands, 2009.

30. Westcott, M.; Sato, S.; Mrazek, D.; Wallace, R.; Vanka, S.; Hardin, D. The DMI Design Value Scorecard: A new Design Measurement and Management Model. Des. Manag. Inst. J. 2014, 24, 10-16. [CrossRef]

31. Topaloğlu, F.; Er, Ö. Discussing a New Direction for Design Management through a New Design Management Audit Framework. Des. J. 2017, 20, S502-S521. [CrossRef]

32. Borja De Mozota, B. Design and competitive edge: A model for design management excellence in European SMEs. Des. Manag. J. 2002, 2, 88-103. [CrossRef]

33. Malmberg, L. Building Design Capability in the Public Sector. Expanding the Horizons of Development. Ph.D. Thesis, Linköping University, Linköping, Sweden, 2017.

34. Liedtka, J. Evaluating the impact of design thinking in action. In Proceedings of the Academy of Management Proceedings, Atlanta, GA, USA, 4-8 August 2017.

35. Relich, M.; Nielsen, I.; Bocewicz, G.; Smutnicki, C.; Banaszak, Z. Declarative modelling approach for new product development. IFAC-Pap. 2020, 53, 10525-10530. [CrossRef]

36. Relich, M.; Świć, A.; Gola, A. A knowledge-based approach to product concept screening. In Proceedings of the Distributed Computing and Artificial Intelligence, 12th International Conference, Salamanca, Spain, 3-5 June 2015; pp. 341-348.

37. Relich, M. A knowledge management system for evaluating the potential of a new product. In Proceedings of the 21st European Conference on Knowledge Management, Coventry, UK, 3-4 September 2020; pp. 668-676.

38. Cousins, B. Validating a Design Thinking Strategy: Merging Design Thinking and Absorptive Capacity to Build a Dynamic Capability and Competitive Advantage. J. Innov. Manag. 2018, 6, 102-120. [CrossRef]

39. Magistretti, S. Framing the microfoundations of design thinking as a dynamic capability for innovation: Reconciling theory and practice. J. Prod. Innov. Manag. 2021, 1-23. [CrossRef]

40. Vavrík, V.; Gregor, M.; Grznár, P.; Mozol, Š.; Schickerle, M.; Ďurica, L.; Marschall, M.; Bielik, T. Design of manufacturing lines using the reconfigurability principle. Mathematics 2020, 8, 1227. [CrossRef]

41. Fratini, L.; Ragai, I.; Wang, L. New trends in Manufacturing Systems Research 2020. J. Manuf. Syst. 2020, 56, 585-586. [CrossRef] [PubMed]

42. Gola, A.; Pastuszak, Z.; Relich, M.; Sobaszek, Ł.; Szwarc, E. Scalability analysis of selected structures of a reconfigurable manufacturing system taking into account a reduction in machine tools reliability. Maint. Reliab. 2021, 23, 242-252. [CrossRef]

43. European Commission. Innobarometer 2016 - EU Business Innovation Trends Fieldwork; European Commission: Brussels, Belgium, 2016.

44. Design Council. The Design Economy 2018: The state of Design in the UK; Design Council: London, UK, 2018.

45. Storvang, P.; Jensen, S.; Christensen, P.R. Innovation through Design: A Framework for Design Capacity in a Danish Context. Des. Manag. J. 2014, 9, 9-22. [CrossRef]

46. Moultrie, J.; Clarkson, P.J.; Probert, D. A tool to evaluate design performance in SMEs. Int. J. Product. Perform. Manag. 2006, 55, 184-216. [CrossRef]

47. Liedtka, J.; King, A.; Bennett, K. Solving Problems with Design Thinking: Ten Stories of What Works; Columbia University Press: New York, NY, USA, 2013; ISBN 978-0-231-16356-9. 
48. Hands, D. Design Transformations: Measuring the Value of Design. In The Handbook of Design Management; Cooper, R., Junginger, S., Lockwood, T., Eds.; Bloomsbury Academic: London, UK, 2011; pp. 366-378.

49. McKinsey The Business Value of Design; McKinsey \& Company: Chicago, IL, USA, 2018.

50. Corsten, N.; Prick, J. The Service Design Maturity Model. Touchpoint. Serv. Des. J. 2019, 10, 72-77.

51. InVision. The New Design Frontier Astronomical Impact. 2019. Available online: https://www.invisionapp.com/design-better/ design-maturity-model/ (accessed on 11 October 2021).

52. Romme, A.G.L.; Dimov, D. Mixing oil with water: Framing and theorizing in management research informed by design science. Designs 2021, 5, 13. [CrossRef]

53. Romme, A.G.L.; Reymen, I.M.M.J. Entrepreneurship at the interface of design and science: Toward an inclusive framework. J. Bus. Ventur. Insights 2018, 10, e00094. [CrossRef]

54. Ketokivi, M.; Hameri, A. Bridging Practice and Theory: A Design Science Approach. Decis. Sci. 2009, 40, 65-87. [CrossRef]

55. Acklin, C. Design management absorption model: A framework to describe and measure the absorption process of design knowledge by SMEs with little or no prior design experience. Creat. Innov. Manag. 2013, 22, 147-160. [CrossRef]

56. Kaplan, R.S.; Norton, D.P. Putting the Balanced Scorecard to Work. Harv. Bus. Rev. 1993, 71, 134-142.

57. Kaplan, R.S.; Norton, D.P. Focusing Your Organization on Strategy-With the Balanced Scorecard. Harv. Bus. Rev. 1996, 37-43.

58. Jain, R.; Aagja, J.; Bagdare, S. Customer experience-A review and research agenda. J. Serv. Theory Pract. 2017, $27,642-662$. [CrossRef]

59. Morgeson, F.V.; Hult, G.T.M.; Mithas, S.; Keiningham, T.; Fornell, C. Turning Complaining Customers into Loyal Customers: Moderators of the Complaint Handling-Customer Loyalty Relationship. J. Mark. 2020, 84, 79-99. [CrossRef]

60. Keiningham, T.L.; Aksoy, L.; Cooil, B.; Andreassen, T.W. Linking Customer Loyalty to Growth. MIT Sloan Manag. Rev. 2008, 49, 51-57.

61. Keiningham, T.L.; Cooil, B.; Aksoy, L.; Andreassen, T.W.; Weiner, J. The value of different customer satisfaction and loyalty metrics in predicting customer retention, recommendation, and share-of-wallet. Manag. Serv. Qual. Int. J. 2007, 17, 361-384. [CrossRef]

62. Fornell, C.; Johnson, M.D.; Anderson, E.W.; Cha, J.; Bryant, B.E. The American Customer Satisfaction Index: Nature, Purpose, and Findings. J. Mark. 1996, 60, 7-18. [CrossRef]

63. Brady, M.K.; Voorhees, C.M.; Brusco, M.J. Service Sweethearting: Its Antecedents and Customer. J. Mark. 2012, 76, 81-98. [CrossRef]

64. Chi, C.G.; Gursoy, D. Employee satisfaction, customer satisfaction, and financial performance: An empirical examination. Int. J. Hosp. Manag. 2009, 28, 245-253. [CrossRef]

65. Larivière, B.; Bowen, D.; Andreassen, T.W.; Kunz, W.; Sirianni, N.J.; Voss, C.; Wünderlich, N.V.; De Keyser, A. “Service Encounter 2.0”: An investigation into the roles of technology, employees and customers. J. Ofbus. Res. 2017, 79, 238-246. [CrossRef]

66. Matzler, K.; Renzl, B. The relationship between interpersonal trust, employee satisfaction, and employee loyalty. Total Qual. Manag. 2006, 17, 1261-1271. [CrossRef]

67. Aranburu, E.; Lasa, G.; Gerrikagoitia, J.K.; Mazmela, M. Case Study of the Experience Capturer Evaluation Tool in the Design Process of an Industrial HMI. Sustainability 2020, 12, 6228. [CrossRef]

68. Karpen, I.; Gemser, G.; Calabretta, G. A multilevel consideration of service design conditions: Towards a portfolio of organisational capabilities, interactive practices and individual abilities. J. Serv. Theory Pract. 2017, 27, 384-407. [CrossRef]

69. Patrício, L.; Gustafsson, A.; Fisk, R. Upframing Service Design and Innovation for Research Impact. J. Serv. Res. 2018, 21, 3-16. [CrossRef]

70. Stickdorn, M.; Lawrence, A.; Hormness, M.; Schneider, J. This Is Service Design Doing, 2nd ed.; O'Reilly: Sebastopol, CA, USA, 2017; ISBN 978-1-491-92718-2.

71. Parasuraman, A.; Zeithaml, V.A.; Berry, L.L. SERVQUAL: A multiple-item scale for measuring consumer perceptions of service quality. J. Retail. 1988, 64, 12-40.

72. Herrera, R.F.; Mourgues, C.; Alarcón, L.F.; Pellicer, E. An Assessment of Lean Design Management Practices in Construction Projects. Sustainability 2020, 12, 19. [CrossRef]

73. He, J.; Ortiz, J. Sustainable business modeling: The need for innovative design thinking. J. Clean. Prod. 2021, $298,126751$. [CrossRef]

74. Shapira, H.; Ketchie, A.; Nehe, M. The integration of Design Thinking and Strategic Sustainable. J. Clean. Prod. 2017, 140, $277-287$. [CrossRef]

75. Maher, R.; Maher, M.; Mann, S.; Mcalpine, C.A. Integrating design thinking with sustainability science: A Research through Design approach. Sustain. Sci. 2018, 13, 1565-1587. [CrossRef] 